\title{
User-centred Design and Literacy Tools for the Deaf
}

\author{
Tania di Mascio and Rosella Gennari \\ 1: University of L'Aquila, Monteluco di Roio, L'Aquila, I-64100, Italy, tania@ing.univaq.it \\ 2: Free University of Bozen-Bolzano, via della Mostra 4, Bolzano, 39100, Italy, gennari@inf.unibz.it
}

\begin{abstract}
Thee need of literacy intervention and of tools for deaf people is largely documented in the literature of deaf studies. This paper aims at eliciting the interests of HCI researchers and practitioners alike on the creation of more intelligent web tools for the literacy of deaf people. Our paper overviews several e-tools for the literacy of the deaf, and it assesses them according to the user centred design methodology. It concludes with a proposal, namely, a first set of guidelines for designing usable e-tools for deaf people, and calls for a debate on the need of a deaf user centred design.
\end{abstract}

\section{Introduction}

The reading delay of deaf people is largely documented, e.g., see [15, 17, 18]. However, their literacy in a verbal language (VL) is varied and can depend on several factors [12]. Recent research in information technology has concentrated on the creation of e-tools for sign languages (SLs), notably, e-dictionaries [2]-roughly speaking, an SL is a gestural-visual language with signs as lexical units, whereas a $\mathrm{VL}$ is an oral-auditive language with words as lexical units. Information technologists seem to be paying less attention to the development of e-tools for improving deaf people's literacy in VLs (simply literacy, onwards). However, the latter is also a critical issue, as substantiated by linguists and psychologists working in deaf studies, crucial for the integration of deaf people into the hearing society.

When it comes to designing for people with disabilities, the popular terms are "adaptive" and "assistive". To the best of our knowledge, nowadays there are no standard usability guidelines specific for designing and developing web tools usable by deaf people.

Our paper describes several e-tools for the literacy of the deaf, reviewing them according to the user centred design methodology (UCDM) $[3,20]$. Why the UCDM? Deaf users have unique and highly variable characteristics, which depend on several factors, such as the degree of deafness, different language instruction methods as well as the level of socio-cultural integration; classifying deaf users as well-known user types is difficult.

The UCDM can be helpful in this respect; it places the users at the centre of the design process; a web tool becomes then truly accessible by deaf users if it is usable by them, being designed and evaluated iteratively with deaf users. Moreover, the UCDM foresees multidisciplinary competences, and a literacy e-tool for the deaf usually require them, for instance, the e-tool may demand the competencies of 
linguists that are expert of deaf studies. This paper also serves to substantiate such claims.

Supported by the findings of deaf studies, our own experience and the review of etools for the deaf, we conclude this paper with a challenge: building on the UCDM, we advance a first set of guidelines for designing usable literacy e-tools for deaf people.

\section{A Review of Literacy E-tools for the Deaf}

This section reviews some e-tools for the deaf, selected because they are web tools, or they include artificial intelligence techniques or technologies, or they adopt user design methodologies. An orthogonal and equally relevant criterion for our selection is that the review should cover diverse literacy aspects, ranging from word knowledge to global reasoning on texts. Table 1 offers a bird-eye view of the tools, and it assesses whether the tools are meant for children or adults.

\section{Description of the Tools}

CornerStones is a tool for teachers of early primary-school children who are deaf, or have visual learning capabilities and literacy problems; see $[11,4]$.

LODE is a web tool for children who are novice readers, primarily deaf children. It tackles the global comprehension of written stories, by stimulating children to correlate events of the stories through apt exercises. The exercises are created and resolved in real time by means of a constraint programming system; see [8, 10].

SMILE is not an application for improving the literacy of deaf children, instead, it helps them learn mathematics and science concepts; see [1, 16]. SMILE is mentioned here because it adopts the UCDM.

The primary goal of ICICLE is to employ natural language processing and generation to tutor deaf students on their written English; see [14,9]. At the time of writing, an ICICLE prototype was not available, hence we could not test it.

MAS (Making Access Succeed for deaf and disabled students) was a project for improving the reading comprehension of deaf signers; see [7, 13]. SIMICODE 2002 (SIMICODE) is a web tool developed within MAS. The tool is made up of thirty hypertexts related to ten themes; a human tutor is necessary for the feedback.

Finally, we analyse some e-dictionaries for deaf people; there is quite a literature on e-dictionaries for SL, which impels us to include them in our review although they are not, strictly speaking, e-tools for the literacy in a VL [2]. Here, we confine our analysis to three case studies, chosen because: they are bimodal dictionaries, that is, dictionary from a SL to the VL of the same country and vice-versa; they are for the web, or adopt a user centred design, or are intelligent.

MM-DASL (Multimedia Dictionary of American SL) was conceived by Sherman Wilcox and William Stokoe in 1980; see [19]. Albeit it was not a web dictionary (at the time of the creation of MM-DASL, the web was not an option), it was a pioneering work in the world of e-dictionaries, and its interface is intelligent. 
Woordenboek is a web bilingual dictionary for Flemish SL (VGT); see [21]. Users search for a sign by selecting its sign components. However, users are not expertly guided through the definition of the sign (i.e., there is no artificial intelligence in the tool), thus users can easily specify a gesture that corresponds to no VGT sign, or a sign that does not occur in the dictionary database.

The creation of a web dictionary for Italian SL (Lingua Italiana dei Segni, LIS) is part of the e-LIS project, which commenced at the end of 2004, see [5,6]. The e-LIS dictionary from LIS to verbal Italian is based on a sign ontology which constraints and guides the users in composing their sign.

\section{The Tools and the UCDM}

Table 1 summarises the main features of the reviewed e-tools. SMILE, LODE, e-LIS explicitly refer to the UCDM; the remaining e-tools do not seem to mention the UCDM or other methodologies with the user at the centre of the design process.

Table 1. Reviewed literacy e-tools for the deaf.

\begin{tabular}{|c|c|c|c|c|c|}
\hline Tool & $\begin{array}{l}\text { For } \\
\text { the } \\
\text { web }\end{array}$ & $\begin{array}{l}\text { Use of } \\
\text { Artificial } \\
\text { Intelligence }\end{array}$ & $\begin{array}{l}\text { For } \\
\text { adults }\end{array}$ & $\begin{array}{l}\text { For } \\
\text { children }\end{array}$ & $\begin{array}{l}\text { Use of } \\
\text { UCDM }\end{array}$ \\
\hline CornerStones & No & No & No & Yes & No \\
\hline LODE & Yes & $\begin{array}{l}\text { Yes (constrain } \\
\text { programming) }\end{array}$ & No & Yes & Yes \\
\hline SMILE & No & No & No & Yes & Yes \\
\hline ICICLE & No & $\begin{array}{l}\text { Yes (natural } \\
\text { language } \\
\text { processing) }\end{array}$ & Yes & No & No \\
\hline MAS & Yes & No & Yes & No & No \\
\hline MM-DASL & No & $\begin{array}{l}\text { Yes (database } \\
\text { technologies) }\end{array}$ & Yes & Yes & No \\
\hline Woordenboek & Yes & No & Yes & Yes & No \\
\hline
\end{tabular}




\begin{tabular}{l|l|l|l} 
e-LIS & $\begin{array}{l}\text { Yes }(\text { OWL }+ \\
\text { query tool })\end{array}$ & Yes & Yes
\end{tabular}

However, by analysing the literature, we can find aspects of the tools that pertain to the UCDM, namely, the context of use, the user requirements, if there is a prototype and its evaluation. The results of our analysis are summarised in Table 2.

The context of use is the primary context for which the tool is developed; home indicates any environment in which the user feels at ease. For instance, the context of use of SMILE is the virtual world. The user requirements are not necessarily those of the end user; they are usually the requirements that characterise the end user according to the designers, that is, they coincide with the usability goals of the tool.

As Table 1 shows, not all the tools have a prototype yet; sometimes, the existing prototypes are still in the initial stage of development, and it is unclear whether they underwent any evaluation. This likely depends on the intrinsic difficulties of developing tools for not clearly defined users, and calls for a set of guidelines that can help designers in developing literacy e-tools usable by the deaf.

Table 2. Reviewed literacy e-tools and the UCDM.

\begin{tabular}{|c|c|c|c|c|}
\hline Tool & $\begin{array}{l}\text { Context } \\
\text { of use }\end{array}$ & $\begin{array}{l}\text { User } \\
\text { requirements }\end{array}$ & $\begin{array}{l}\text { Design - latest } \\
\text { product }\end{array}$ & Evaluation \\
\hline CornerStones & $\begin{array}{l}\text { Primary } \\
\text { school }\end{array}$ & VL literacy & Web demo & Yes \\
\hline LODE & $\begin{array}{l}\text { Home or } \\
\text { primary } \\
\text { school }\end{array}$ & VL literacy & Web demo & Yes \\
\hline SMILE & $\begin{array}{l}\text { Virtual } \\
\text { world }\end{array}$ & $\begin{array}{l}\text { Science } \\
\text { literacy }\end{array}$ & Downloadable & Yes \\
\hline ICICLE & Home & VL literacy & Unavailable & Unclear \\
\hline MAS & Home & VL literacy & Unavailable & Yes \\
\hline MM-DASL & Home & SL literacy & Discontinued & Unclear \\
\hline Woordenboek & Home & SL literacy & Web prototype & Unclear \\
\hline
\end{tabular}




\begin{tabular}{|l|l|l|l}
\hline e-LIS & Home & SL literacy & Web prototype
\end{tabular}

\section{Towards a Deaf User Centred Design}

\section{Know your users}

Deaf studies are mainly authored by psychologists, linguists and educators, and not by usability experts. User centred designers should include such studies and interview experts of deaf studies, in particular for establishing the context of use and the user requirements of their tools for the deaf. Albeit the reviewed e-tools for the deaf do not explicitly mention the UCDM, their designers implicitly follow it whenever they consult and collaborate with experts of deaf studies.

Designers may have problems in communicating directly with deaf users, as these may prefer their SL or simply tend to distrust unfamiliar people. Therefore the designers may require the assistance of interpreters or, more in general, intermediaries that deaf users are familiar with, for instance, the parents or a teacher of a deaf child.

In designing and evaluating a web tool for the deaf, control groups of hearing people can also be of assistance or even necessary; in this setting, control groups are formed by hearing people with a profile similar to the intended deaf users' profile.

This is all in accordance with the UCDM, which foresees the presence of different users, besides the end-users, in the development process. Table 3 classifies the users that we believe are necessary in the UCD of a web tool for the deaf, in line with the literature of deaf studies and our review of e-tools for the deaf.

However, ours is a coarse-grained classification. The assistance of experts of deaf studies and intermediaries is highly recommended for fine-tuning the classification for the specific e-tool under development, and its specific users. Therefore, in the remainder of this paper, we advance a first set of guidelines for developing a deaf user centred design methodology.

\section{UCDM Guidelines}

Given the types of users that we summarised in Table 3, the iterative process for designing the e-tool can start. First, the context of use is analysed, then the user requirements are established. A first prototype is designed and evaluated. The results of the evaluations are checked against the user requirements, which can be refined, and the iteration may restart. In the remainder, we provide a concrete guide to each step of the iteration and highlight some User Evaluation Methodologies (UEMs) that designers could employ.

Table 3. Types of users.

\begin{tabular}{l|l} 
User types & Description \\
\hline End users & The deaf people for which the tool is developed \\
\hline Usability experts & HCI experts
\end{tabular}




\begin{tabular}{l|l} 
Deaf study experts & $\mathrm{HCI}$ experts \\
\hline Intermediaries & $\begin{array}{l}\text { People who are familiar with the end users, e.g., the parents of } \\
\text { a deaf child }\end{array}$ \\
\hline Control users & Hearing people with a profile similar to that of the end users
\end{tabular}

\section{Context of use}

The design team should analyse the state of the art, mainly through the literature of deaf studies and ad-hoc inquiries with experts of deaf studies. These and intermediaries are also essential for refining the classification of the tool's end users. For instance, let us consider LODE, a literacy tool for children; the experts of deaf studies may help in focusing the range of application of the tool, as well as in understanding whether it makes sense to classify deaf children according to their language education, e.g., oral or bimodal, or whether the children's age is a more relevant factor.

Such experts and intermediaries can also assist in choosing the best context for evaluating or using the tool. Again, let us reconsider the case of LODE as example; experts and intermediaries may suggest whether the child's home is more apt than a school lab for testing or using the tool.

Suggested UEM's in this stage of development are: inquiries with experts of deaf studies.

\section{Definition and analysis of the user requirements}

In order to establish the user requirements, designers should consult with experts of deaf studies and HCI. Experts in deaf studies help in setting on firmer grounds the requirements, e.g., if the tool is meant for correcting a specific type of grammatical errors, like ICICLE, then the experts could confirm whether the tool's end users commit such type of errors, or that the type of feedback of the tool is indeed useful.

Then the designers should assess the requirements with the end users, with the assistance of intermediaries. The assessment can be done via structured inquiries, or observational evaluations. These evaluations should be organised right at this stage of the project, even with small groups of end users given the difficulty in recruiting deaf users for tests, and possibly with a control group; controlled evaluations will assess whether there are significant differences between the two types of users. For instance, let us reconsider a web tool for improving the grammatical production of deaf signers. In the analysis of user requirements, the observation and comparison of a group of deaf users and a group of hearing users working with the tool can serve to ascertain a significant difference between the grammatical productions of the two groups, and which grammatical interventions may be more suited to the former group of users.

One should also consider that deaf people, and deaf signers in particular are often organised in networks; a positive experience within the network can spread rapidly and elicit more deaf uses to participate in future evaluations of the tool. Moreover, such tests will also serve to assess the most comfortable environment for the users, the best test timing, hardware equipment etc. 
With deaf signers, the assistance of an SL interpreter is highly desirable during the tests; similarly, deaf children may need the assistance of a person they trust and that can work as intermediary. To this end, the evaluators should gather information on the participants with questionnaires, prior to the observational evaluations; in this manner, the evaluators can assess if the their deaf participants need interpreters, their first language (VL or SL), their level of acquaintance with computers, ...

Suggested UEM's in this stage of development are: inquiries with experts of HCI and experts of deaf studies; inquiries, observational evaluations and controlled evaluations with even a small group of deaf users and a control group.

\section{Design and evaluation}

The designers should produce several prototypes, even paper and pencil drawings. We detail such steps in the remainder of this paper.

Specific features of the first prototype should be evaluated with experts of deaf studies and HCI. As soon as possible, the subsequent prototypes should be evaluated with even a small number of the intended end users and a control group, observed while interacting with the tool; the results should be then compared with controlled evaluations. For instance, let us reconsider the case of a literacy tool such as LODE, which aims at stimulating children to globally reason on written stories. Generally at around the age of 8 , children are novice readers, they start reasoning globally on a story and deducing logical relations among episodes of the story - all critical steps for developing an expert literacy. The usability of a mature prototype of LODE is thus tested with deaf children and a control group composed of hearing novice readers, that is, 7-8 year old children.

As the design cycle progresses, the evaluators should recruit a significant number of deaf users and observe them while they are interacting with the tool. It may be easier to have a number of these evaluations of the same prototype with few users.

In general, designers should consult with experts along the whole design process: experts of deaf studies help to ensure that the prototypes meet the end-user requirements; experts of HCI serve to ensure that the prototypes fulfil the usability goals. Intermediaries should assist designers along the observational evaluations. They can also help in structuring the inquiries for gathering information prior as well as post evaluations.

Suggested UEM's in this stage of development are: expert-based evaluations with usability experts; observational evaluations and inquiries with experts of deaf studies; observational evaluations and inquiries with deaf users; observational evaluations and inquiries with control groups; controlled evaluations. 


\section{Conclusions}

Our review of literacy e-tools for deaf people showed that there are several e-tools for the deaf that cover diverse aspects of literacy, e.g., in-depth context-based knowledge of words, global reasoning on stories, grammatical aspects of text production.

According to our review, some e-tools lack or do not have a clear evaluation. This is very likely due to the absence of assessed guidelines for developing e-tools for deaf people, usable by deaf people, with deaf users at the centre of the design process.

Thereby this paper advances a first set of such guidelines, based on the UCDM; they emerge from our own experience in developing web tools for deaf people, the multidisciplinary findings of deaf studies, the analysis of the literature and of several literacy e-tools for the deaf.

The guidelines aim to ease the design of new tools for the deaf, to improve the development of existing tools and, more ambitiously, to open a debate within HCI on the creation of a deaf user centred design. We hope that more HCI researchers and practitioners, elicited to work on e-tools for the deaf, will assess the guidelines, and contribute to the debate.

\section{References}

[1] N. Adamo-Villani and K. Wright. SMILE: an Immersive Learning Game for Deaf and Hearing Children. In SIGGRAPH 2007, San Diego, USA, August 2007. ACM.

[2] J. Branson and D. Miller. Research Methods for Studying the Language of the Signing Deaf. In Encyclopedia of Language and Education. Horneberger, N. and Corson, P., 1997.

[3] A. Chadia, D. Maloney-Krichmar, and J. Pree. User-Centered Design. In W. Bainbridge, editor, Encyclopedia of Human-Computer Interaction, pages 763-778. Berkshire, 2004.

[4] CornerStones Working Group. Retrieved December 23 2008, from http://ncam.wgbh.org/cornerstones/cornerstones.html.

[5] T. Di Mascio and R. Gennari. An Intelligent Visual Dictionary for Italian Sign Language. Journal of Web Engineering, 7(4), 2007.

[6] e-LIS Working Group. Retrieved January 22009 from http://elis.eurac.edu/diz/.

[7] A. Ferrer, R. Romero, M. Martìnez, M. Asensi, and A. Andreu. Improving Reading Skills in Adult Deaf People: The Spanish MAS Module.

[8] R. Gennari and O. Mich. Constraint-based Temporal Reasoning for E-learning with LODE. In Proc. of CP 2007. Springer, 2007.

[9] ICICLE Working Group. Retrieved December 23 2008, from http://www.eecis.udel.edu/research/icicle/.

[10] LODE, working group. Retrieved January 14, 2009, from http://www.inf.unibz.it/lode, 2008.

[11] M. Loeterman, P. Paul, and S. Donahue. Reading and Deaf Children. Reading Online, 6(5), 2008.

[12] M. Marschark and P. Spencer. Oxford Handbook of Deaf Studies, Language and Education. Oxford University Press, 2003.

[13] MAS Working Group. Retrieved January 22009 from http://acceso.uv.es/mas/index.html, 2002.

[14] L.N. Michaud and K.F. McCoy. Capturing the Evolution of Grammatical Knowledge in a CALL System for Deaf Learners of English. International Journal of Artificial Intelligence in Education (IJAIED), 16(1):65-97, 2006. 
[15] B. Schirmer and C. Williams. Approaches to Teaching Reading. In M. Marschark and P. Spencer, editors, Handbook of Deaf Studies, Language and Education. Oxford University Press, 2003.

[16] SMILE Working Group. Retrieved December 23 2008, from http://www2.tech.purdue.edu/cg/i3/SMILE/.

[17] C. B. Traxler. The Stanford Achievement Test, 9th Edition: National Norming and Performance Standards for Deaf and Hard-of-hearing Students. Journal of Deaf Studies and Deaf Education, 5:337-348, 2000.

[18] L. N. Wauters, W. H. J. van Bon, and A. E. J. M. Tellings. Reading Comprehension of Dutch Deaf Children. Reading and Writing, 19:49-76, 2006.

[19] S. Wilcox. The Multimedia Dictionary of American Sign Language: Learning Lessons about Language, Technology and Business. Sign Languages Studies, iii(4):379-392, 2003.

[20] W. Woodson. Human Factors Design Handbook. McGraw-Hill Education, 1981.

[21] Woordenboek Working Group. Retrieved January 22009 from http://gebaren.ugent.be/visueelzoeken.php. 